\title{
Sistema de Tutoria a Distância: Análise da Mediação em Fóruns Colaborativos em Ambientes Virtuais de
} Aprendizagem

\author{
Andréa Neves Nogueira Rochefeller*1, IIdenice Lima Costa²
}

\begin{abstract}
${ }^{1}$ Especialista em Planejamento, Implementação e Gestão da Educação a Distância / LANTE - Laboratório de Novas Tecnologias de Ensino / Instituto de Matemática e Estatística / Universidade Federal Fluminense UFF. Rua Mário Santos Braga s/n. Valonguinho, 24.020-140. Niterói-RJ - Brasil. arochefeller@id.uff.br

2 Mestre em Educação pela Universidade de Brasília (UnB) / Especialista em Planejamento, Implementação e Gestão da Educação a Distância / LANTE - Laboratório de Novas Tecnologias de Ensino / Instituto de Matemática e Estatística / Universidade Federal Fluminense - UFF. Rua Mário Santos Braga s/n. Valonguinho, 24.020-140 - Niterói-RJ - Brasil. ildenicelc@gmail.com
\end{abstract}

\section{Resumo}

Este trabalho tem como objetivo identificar e descrever um sistema de tutoria capaz de fornecer subsídios aos alunos de curso de especialização realizado em ambiente virtual de aprendizagem (AVA). A partir da concepção da mediação de trabalhos colaborativos, foram investigadas formas de propiciar a aprendizagem autônoma discente. O enfoque no aspecto colaborativo apresenta-se como alternativa para integrar práticas de pesquisa e solução de problemas existentes nos fóruns e tarefas a partir das máximas conversacionais. Neste trabalho focou-se em diferentes contextos que envolvem as funções do tutor a distância, na busca da promoção de um ambiente virtual em que o aluno possa perceber-se como ser integrado. A pesquisa reforça a importância do trabalho do tutor para a promoção da aprendizagem dos alunos em cursos a distância na percepção do trabalho colaborativo. O público-alvo é composto de tutores e alunos de um curso de especialização promovido no Estado do Rio de Janeiro. Para tanto, foram analisadas mensagens nos fóruns no AVA em que o curso foi ofertado postadas em uma das disciplinas, ocorrida no segundo semestre de 2013, disponibilizada na plataforma Moodle.

Palavras-chave: Sistema de tutoria, Ambiente colaborativo, Máximas conversacionais, AVA. 


\title{
System Mentoring Distance: Mediation Analysis Forums Collaborative Learning in Virtual Environments - AVA
}

\begin{abstract}
This paper aims to identify and describe a mentoring system, capable of providing subsidies to students specialization course held in virtual learning environment - AVA. From the conception of mediation collaborative work, ways to promote the student autonomous learning were investigated. The focus on collaborative aspect is presented as an alternative to mainstream research practices and problems solution in forums and tasks, from the conversational maxims of Grice, 1957. In this work focused in different contexts involving tutor functions away in search of promoting a virtual environment where the student can be perceived as being integrated. The research reinforces the importance of the tutor's work to promote student learning in distance learning courses in the perception of collaborative work. The target audience is composed of tutors and students a specialization course promoted in the state of Rio de Janeiro. Therefore, messages in the forums were analyzed in AVA in which the course was offered, posted on one of the subjects in the second half of 2013, available in Moodle.
\end{abstract}

Keywords: System of mentoring, Collaborative environment, Conversational maxims, AVA. 


\section{Introdução}

Os cursos profissionalizantes realizados por meio de correspondência foram o marco inicial do ensino a distância no Brasil, a partir da metade do século XIX. Somente com a chegada de novas tecnologias e propostas inovadoras de educação esse instrumento foi substituído por novas ferramentas educacionais.

Esta pesquisa pretendeu reforçar a importância do trabalho do tutor para a promoção da aprendizagem dos alunos em cursos a distância e perceber, dentro do paradigma dos sistemas de tutoria em cursos a distância, a importância do trabalho colaborativo nas turmas de ambientes online. Compatibilizou-se metodologia mista para coleta de dados, preferencialmente em um curso de especialização a distância, disponibilizado na plataforma Moodle.

O propósito geral deste trabalho foi descrever os sistemas de tutoria com base em uma mediação pedagógica colaborativa e verificar como essa contribuição pode auxiliar nas relações entre tutores e alunos de forma dialógica, bem como o desenvolvimento intelectual e cognitivo do aluno.

Inicialmente, a proposta foi caracterizar o ambiente educacional do curso de especialização a distância: cenário, atores e tarefas e a perspectiva de atuação do tutor em meio aos desafios que se evidenciam na EaD. Outros objetivos que delinearam a pesquisa: descrever o sistema de tutoria de curso de especialização a distância; analisar o perfil de atuação de tutores no AVA a partir de pesquisa realizada com tutores de curso de especialização a distância; destacar formas de atuação que auxiliem nas relações e nos resultados formativos obtidos pelos alunos. Por fim, identificar as estratégias utilizadas pelos tutores na mediação e motivação dos alunos/cursistas e analisar situações no ambiente virtual de aprendizagem que denotam a necessidade do uso da dialogicidade e expressão verbal dos tutores no ambiente virtual, de forma a perceber os mecanismos que contribuem para a compreensão e a aprendizagem dos alunos.

\section{Procedimentos metodológicos}

Esta pesquisa exploratória teve por objetivo depreender, em uma mediação pedagógica colaborativa, os aspectos necessários a essa metodologia em cursos de especialização em ambientes virtuais de aprendizagem que podem auxiliar as relações, de forma dialógica, entre tutores e alunos. A estes compete realizar suas atividades em 
grupo, utilizando-se do trabalho colaborativo. O público-alvo pesquisado foi composto de tutores e alunos de um curso de especialização promovido no Estado do Rio de Janeiro. Para tanto, foram analisadas mensagens nos fóruns no ambiente virtual de aprendizagem (AVA) em que o curso foi ofertado postadas em uma das disciplinas oferecidas no segundo semestre de 2013.

O corpus de postagens analisadas foi formado por mensagens dos fóruns temáticos avaliativos, os quais ficaram abertos no último bimestre de 2013 e contaram com a participação de 96 alunos e 9 tutoras. As mensagens enviadas pelos alunos e tutoras foram editadas. Primeiramente foi realizada uma leitura exploratória. $O$ estudo em questão tem abordagem qualitativa, uma vez que permite verificar alternativas diversas para responder às questões pertinentes ao universo em estudo, pois, uma vez conectados, os alunos da EaD utilizam as mais variadas estratégias de comunicação.

O modelo pedagógico utilizado para análise foi trabalho colaborativo em grupo, pois dessa maneira verificou-se a atividade dos estudantes que participam e aprendem uns com os outros nos grupos em que foram inseridos. Os instrumentos utilizados para a coleta de dados são os fóruns do ambiente virtual de aprendizagem.

$\mathrm{Na}$ análise dos dados, considerou-se analisar as mensagens postadas por alunos e tutoras à luz da pesquisa bibliográfica realizada, pois esta permitiu reconhecer os dados apresentados a partir de informações constituídas em outras instâncias.

\section{Pressupostos teóricos}

Neste capítulo são apresentados o sistema de tutoria do curso online em estudo, o sentido das relações sociais na EaD e as características da dialogicidade e da colaboratividade realizadas a partir da prática conversacional pedagógica no ambiente virtual. Tais ações permitem ao tutor viabilizar as interações no espaço da plataforma, na perspectiva da aprendizagem a distância. Os conceitos referentes aos princípios de cooperação e as máximas conversacionais explicitam a compreensão sobre as interações estabelecidas entre tutor/aluno. 


\subsection{Sistema de tutoria}

O ambiente educacional do curso de especialização a distância em estudo apresenta como características o cenário, atores e tarefas, bem como a perspectiva de atuação do tutor em meio aos desafios que se evidenciam na EaD descritos nesta seção.

A instituição do curso em estudo buscou criar seu modelo tutorial atendendo às especificidades locais na promoção de interação entre tutores e alunos. Os sujeitos da aprendizagem do curso em questão são mencionados a seguir.

O coordenador de tutoria (CT) acompanha a trajetória dos tutores da disciplina, orientando-os em relação a prazos e padrões de atuação e quanto às competências que estarão em pauta no exercício da sua função. É acompanhado por um coordenador geral de tutoria, que o auxilia no contato com o coordenador da disciplina.

O coordenador geral de tutoria (CGT) cuida das demandas da tutoria junto às coordenações do curso e aos demais setores envolvidos na oferta do curso. As funções do CGT são:

1. abertura de disciplinas - configuração e edição do AVA;

2. acompanhamento de todo o processo tutorial, em um trabalho colaborativo e estratégico com o professor coordenador de disciplina e com a coordenação do curso;

3. acompanhamento contínuo e avaliação do processo tutorial e da atuação dos tutores;

4. acompanhamento de lançamento de notas e prazos para entrega de tarefas;

5. análise de resultados obtidos e propostas de melhoria;

6. atendimento às demandas da tutoria junto à coordenação do curso e aos demais setores envolvidos na oferta do curso;

7. atualização diária na plataforma Moodle, verificando sua funcionalidade e falhas no sistema;

8. confecção de calendário do curso;

9. elaboração de guia da disciplina e cronograma da disciplina;

10. envio e inclusão de mensagens oriundas da coordenação geral do curso;

11. inclusão de usuários e seleção de grupos de alunos e tutores - administração do site/curso; 
12. inclusão e adequação no AVA de materiais didáticos, mídias e bibliografias utilizadas para o desenvolvimento da disciplina;

13. relatório geral de notas dos alunos, de acordo com os grupos formados.

O coordenador da disciplina gerencia a disciplina e coordena as ações relacionadas ao desenvolvimento do projeto pedagógico e sua implementação, bem como sua revisão. O tutor deve atuar junto ao coordenador da disciplina; colabora complementando o seu trabalho, auxilia na elaboração e no aperfeiçoamento de orientações para os alunos referentes ao conteúdo pedagógico das disciplinas (texto-base, fórum temático e tarefa), na revisão do material didático e participando ainda mais diretamente da correção das tarefas dos alunos, de acordo com os critérios fixados pelo coordenador da disciplina.

Os elementos da aprendizagem neste curso a distância são:

- $\quad$ material didático: constitui-se por uma série de textos-base e atividades que integram cada unidade. O desenho instrucional da disciplina favorece a interatividade e a autoinstrução;

- $\quad$ atividades e avaliações: são visualizadas a partir da data de início de cada unidade, ao meio-dia das quartas-feiras. O prazo final para entrega das atividades ocorre sempre às terças-feiras às $23 \mathrm{~h} 55 \mathrm{~min}$. As atividades propostas devem ser realizadas ao longo dos estudos de cada unidade.

Essa forma de atuação do sistema de tutoria favorece inicialmente o planejamento, a organização e a gestão do curso a distância, possibilitando um aprendizado efetivo aos discentes.

\subsection{O sentido das relações sociais na EaD}

Relações sociais são estabelecidas no ambiente virtual de aprendizagem (AVA). Os alunos passam a constituir grupos de relacionamentos estreitos, como no ensino presencial. Alguns passam a interagir utilizando as redes sociais, sejam elas físicas (de forma presencial) ou virtuais (pela internet), firmando-se em grupos que trabalharão juntos durante parte do processo acadêmico.

A humanização do ambiente de ensino a distância apresenta-se como uma das mudanças mais significativas nessa modalidade de ensino ao longo dos anos, a partir da progressiva evolução do acesso à EaD e sua ressignificação na educação moderna, em tempos de tecnologias digitais. 
As interações realizadas entre todos os partícipes do contexto de um curso a distância tornam-se instrumentos de apoio ao trabalho colaborativo e, dessa forma, ao próprio aprendizado.

\subsection{Aprendizagem colaborativa: uma proposta social}

Fica evidente na fala de Stahl et al. (2006, p. 3) sobre o termo aprendizagem colaborativa que todos os indivíduos que estão envolvidos como membros de um grupo utilizam-se da negociação e compartilhamento como formas de interagir e aprender desde que não sejam atividades de aprendizagem individual. Dessa forma, eles não se isolam para realizar suas atividades individualmente, pois se engajam em uma tarefa compartilhada que é construída e mantida pelo e para o grupo.

Martins (2011) relata que o fórum sem mediação não realiza seu papel de atividade dialógica e interacionista. Assim sendo, solicitar expressamente a colaboração dos alunos torna-se para o tutor uma tarefa desafiadora, bem como mostrar-se receptivo à participação, observando todas as nuances do trabalho, em especial na percepção tênue sobre as falas dos alunos para motivá-los à realização dos trabalhos individuais e, principalmente, em grupo.

Stahl et al. (2006) caracterizam a importância da aprendizagem dos alunos entre si, ao invés de ocorrer apenas entre eles e o professor. A utilização de e-mails, chats, fóruns de discussão, videoconferências, programas de mensagens instantâneas, redes sociais etc. tem, com funcionalidades especiais adicionadas, o intuito de promover não somente a interação, mas também a aprendizagem colaborativa.

Por meio dos trabalhos colaborativos, é possível ao professor/tutor instigar o aluno a elaborar conceitos, propondo-lhe individualmente que assuma o compromisso de pesquisar e contribuir autonomamente nas classes virtuais. Assim sendo, como afirmam Sihler e Ferreira (2011, p. 9), o papel do professor/tutor é importante, pois cabe a ele instigar e despertar no aluno o interesse e a curiosidade em prosseguir e ir além do que Ihe é oferecido, o que vem garantir sua permanência no curso. Dessa forma, o tutor pode ser considerado um dos grandes responsáveis pela permanência ou desistência do aluno que estuda na modalidade a distância. 


\subsection{A dialogicidade como auxiliar na atuação do tutor em EaD}

Nessa modalidade de aprendizagem a distância, faz-se necessário perceber novas perspectivas nas didáticas empregadas, as formas com as quais os conhecimentos se darão e a amplitude de oportunidades que o trabalho colaborativo, associado às redes sociais, poderá proporcionar.

Ao relacionar tal fator à ação do tutor, na percepção de Vigotski (1989) considerase que, ao organizar o aprendizado, ele irá contribuir para a promoção do desenvolvimento mental dos seus alunos, colocando em movimento vários processos de desenvolvimento que seriam impossíveis de acontecer caso tal organização não ocorresse.

Ao refletir sobre o processo de tutoria, Dotta e Giordan (2007) observam que outros elementos podem ser abordados nos programas de formação de educadores, além da preparação técnica para uso de ferramentas de comunicação a distância ou de ambientes virtuais de aprendizagem:

- a emergência de signos incomuns à linguagem escrita tradicional;

- o surgimento de novos gêneros discursivos;

- o conceito de educação dialógica e a importância do diálogo problematizador.

Tais fatores contribuem para a construção de significados e a reflexão e debate sobre se um processo de tutoria pela internet fundado na dialogia pode imprimir diferenças no processo de aprendizagem.

A dialogicidade, segundo Bakhtin (2003), será necessária ao trabalho do tutor a distância, pois este deve estar presente no AVA diariamente e responder aos alunos cursistas, que devem ser estimulados a desenvolver suas atividades no prazo estipulado por meio de respostas motivadoras às seguintes situações: participação e discussão nos fóruns, e-mails individuais, elaboração de plano de estudo, participação em chats temáticos e de esclarecimento de dúvidas, feedbacks dos trabalhos entregues e correção das atividades no prazo estipulado.

Certamente Maia e Lannes (2013) asseguram que o tutor é um elemento indispensável, atuando com parceria para oferecer estímulo para a aprendizagem e o incentivo à reflexão, motivando os alunos à participação na rede de comunicação que 
vincula os cursistas à instituição de ensino. Isso possibilita a retroalimentação acadêmica e pedagógica do processo educativo.

Ilha et al. (2009) consideram que o trabalho colaborativo e o trabalho do tutor são formas de auxiliar na construção da autonomia do aluno e meio de sistematizar os conhecimentos entre professores, tutores e alunos. Consequentemente, o tutor pode responder às perguntas, esclarecer dúvidas, orientar, motivar, promover debates entre os participantes, entre outras ações, mas tendo como meta prioritária levar o aluno a uma reflexão crítica, formal e autônoma para cada participação, o que contribui para reafirmar e ordenar conceitos.

\subsection{Os princípios de cooperação e as máximas conversacionais}

De acordo com vários estudos da Pragmática (teoria do uso linguístico na área da Linguística), toda conversação é regida pelo Princípio da Conversação. A partir das implicaturas conversacionais - resultado da adesão ao princípio de cooperação que guiaria a interação verbal (linguística) entre os indivíduos -, o filósofo americano H. P. Grice, cujos estudos iniciais datam de 1957, criou os princípios de cooperação e as máximas conversacionais (Wilson, 2008).

Wilson (apud Grice, 2008) cita ainda que esse princípio geral se desdobra em quatro mais pontuais, para que o diálogo seja bem-sucedido. São eles:

- $\quad$ máxima da quantidade - relacionada com a quantidade de informação.

- $\quad$ máxima da qualidade - está relacionada com as informações verdadeiras.

- $\quad$ máxima da relação - "Seja relevante".

- $\quad$ máxima do modo - "Seja claro".

As máximas conversacionais foram utilizadas neste trabalho com o objetivo de identificar as estratégias utilizadas pelos tutores na mediação e motivação dos alunos/cursistas. Nesse sentido, Nobre e Melo (2011) atentam para uma predisposição do aspecto afetivo como competência mais essencial dentre outras, que também são importantes. Assim, as competências afetivas do mediador tornam-se essenciais à sua prática pedagógica. 


\subsection{A atuação dialógica e colaborativa do tutor}

O tutor, em sua atuação pedagógica, deve mediar o processo das descobertas, participar do processo de elaboração de conceitos de forma impessoal, mostrar caminhos, buscar soluções e estimular a participação de todos. Por meio do diálogo, no ambiente virtual de aprendizagem, pode integrar o educando ao seu próprio processo de ensino-aprendizagem.

Segundo Teles (2009), algumas funções do professor online são necessárias ao trabalho pedagógico a distância.

Quadro 1: As funções do professor online

\begin{tabular}{|c|c|}
\hline $\begin{array}{c}\text { Função } \\
\text { pedagógica }\end{array}$ & $\begin{array}{l}\text { 1. Dar instrução direta; } \\
\text { 2. Realizar perguntas diretas; } \\
\text { 3. Fazer referência a modelos ou exemplos; } \\
\text { 4. Dar conselhos ou oferecer sugestões; } \\
\text { 5. Promover a autorreflexão no estudante; } \\
\text { 6. Guiar os estudantes no processo de encontrar outras fontes } \\
\text { de informação; } \\
\text { 7. Sugerir que os estudantes expliquem ou elaborem melhor } \\
\text { suas ideias; } \\
\text { 8. Oferecer feedback e congratulações pelas contribuições das } \\
\text { discussões online; } \\
\text { 9. Atuar como suporte na estruturação das tarefas cognitivas; } \\
\text { 10. Costurar comentários. }\end{array}$ \\
\hline $\begin{array}{c}\text { Função de } \\
\text { gerenciamento }\end{array}$ & $\begin{array}{l}\text { 1. Gerenciar as ações dos estudantes, encorajando-os a postar } \\
\text { mensagens e entregar trabalhos no prazo; } \\
\text { 2. Administrar discussões e trabalhos de grupos; } \\
\text { 3. Gerenciar a parte administrativa, esclarecendo regras e } \\
\text { expectativas do curso; } \\
\text { 4. Atribuir notas; } \\
\text { 5. Iniciar, concluir e resumir a discussão da disciplina. }\end{array}$ \\
\hline $\begin{array}{c}\text { Função de } \\
\text { suporte social }\end{array}$ & $\begin{array}{l}\text { 1. Empatia: expressões de compreensão em relação às } \\
\text { colocações do estudante; } \\
\text { 2. Alcance interpessoal: atos de fala expressivos, como dar } \\
\text { boas-vindas à disciplina; } \\
\text { 3. Metacomunicação: discussão sobre a experiência de cada um } \\
\text { no ambiente online; } \\
\text { 4. Humor: piadas e brincadeiras. }\end{array}$ \\
\hline $\begin{array}{c}\text { Função de } \\
\text { suporte técnico }\end{array}$ & $\begin{array}{l}\text { 1. Envolve desde a seleção do software apropriado para } \\
\text { preencher os objetivos específicos de aprendizagem da } \\
\text { disciplina; } \\
\text { 2. Ajuda aos estudantes para que se tornem usuários } \\
\text { competentes e confortáveis do software utilizado. }\end{array}$ \\
\hline
\end{tabular}

Fonte: Teles, 2009. 
Estas funções são atos pedagógicos a serem realizados pelo tutor. Cabe a ele, portanto, atuar no gerenciamento do espaço de aprendizagem virtual de forma que seus alunos participem desse processo transformador. Deve, principalmente, fornecer-Ihes os recursos necessários para que, a partir de sua própria realidade, analisem e identifiquem os pontos importantes das informações que receberem, de forma colaborativa. Em consequência disso, os alunos aprendem a criticar e avaliar as informações que obtiverem de forma autônoma.

\section{Análise dos dados}

Esta pesquisa optou por analisar o corpus formado por mensagens postadas nos fóruns temáticos avaliativos e nos fóruns permanentes de uma disciplina ministrada no segundo semestre de 2013. O ambiente virtual de aprendizagem ficou aberto no último bimestre de 2013 e contou com a participação de 96 alunos e 9 tutoras, divididos em grupos. As mensagens postadas pelos alunos e tutoras foram editadas.

Trata-se de estudo interpretativo que, pela análise das postagens, busca verificar alternativas diversas para responder às questões pertinentes ao universo da EaD, focado numa abordagem qualitativa, uma vez que os alunos da EaD são motivados a uma mediação pedagógica colaborativa. As relações entre tutores e alunos ocorrem de forma dialógica. Foram analisados excertos acerca da mediação pedagógica entre tutores e alunos.

A análise dos dados está fundamentada na Teoria da Análise da Conversação e da Pragmática, relacionada ao estudo da linguagem, com o objetivo de identificar as estratégias utilizadas pelos tutores na mediação e motivação dos alunos/cursistas.

Foram utilizados nomes fictícios, com o intuito de preservar o nome da instituição e de seus participantes, tanto alunos e tutores.

A partir das implicaturas conversacionais entre os participantes dos fóruns, analisamos como cada máxima conversacional pode proporcionar um diálogo bemsucedido ou não nas interações ocorridas no ambiente virtual de aprendizagem. 


\subsection{Máxima da quantidade}

No Excerto 01, temos a proposta do Fórum Temático 1: Convite ao texto: reavaliando o trabalho com leitura e escrita na escola. O emissor é a tutora $\mathrm{T} 1$, que se dirige aos alunos do grupo 8.

\section{Olá, Grupo 8!}

Relate uma piada breve e diga o que faz a mesma ser engraçada.

Para tornarmos o fórum mais produtivo, siga a dinâmica AÇÃo e RÉPLICA, comentando o relato de uma(um) colega ou mesmo pedindo algum detalhamento que lhe pareça relevante.

Mantenha-se no limite de $\mathbf{1 0 0}$ palavras em sua escrita.

Bom trabalho!

\section{Critérios de avaliação do fórum:} concisão.

Tome como referência as ideias do texto-base e escreva com coerência interna, coesão e

(5 pontos)

Excerto 01

O uso da linguagem objetiva e concisa, sem elementos não verbais, e o destaque de alguns termos favorecem a construção da motivação por parte da tutora T1 neste excerto 01. Há a proposta de manutenção do limite do número de palavras a ser utilizado no fórum.

As respostas apresentadas no Fórum Temático 1 do grupo 8 são mostradas do Excerto 02 ao 04.

Por Aluno $01-23: 04$

Num corredor do manicómio, um maluco cruza-se com outro e diz:

- O que é que tens, para andares aos "esses" e a arrastar os pés!

Responde o outro:

- É por causa dos sapatos novos!

O primeiro:

- Por causa dos sapatos?! O que é que eles têm?

Diz o outro:

- São feitos de pele de crocodilo.

O humor recai sobre a crença do sujeito de andar conforme os movimentos do crocodilo, já que usava calçados de pele de crocodilo. Para atribuir o mesmo sentido pretendido pelo autor, o leitor terá que compartilhar crenças e valores (Kleiman, 2010).

Excerto 02 
O Aluno 01 (Excerto 02) atende inicialmente ao comando do fórum de discussão, não dando mais informações que o necessário. Respondeu com coerência interna, coesão e concisão, conforme os critérios de avaliação do fórum. O número de palavras também foi respeitado. A mensagem foi tão informativa quanto necessária, respeitando a máxima da quantidade, segundo Grice (1957).

Por Aluno $02-22: 09$

Réplica

Olá, Aluno 01, para que haja entendimento desejado no texto, o autor deverá ter o cuidado de escrever de forma que envolva o contexto do leitor, caso contrário não surtirá o efeito desejado e, no caso da piada, comprometerá o efeito de humor.

\section{Excerto 03}

Neste Excerto 03, o Aluno 02 utilizou-se da réplica para comentar o relato apresentado pelo Aluno 01. Esclareceu seu ponto de vista e atendeu ao critério da dinâmica de réplica.

Por Aluno $02-17: 36$

Ação: - O idioma francês é o mais interessante e útil - dizia uma.

A outra:

- Qual nada! Acho que é o idioma inglês.

Uma outra:

- Mas o que vem a ser idioma?

- Idioma quer dizer uma língua.

- É?! Então fiquem sabendo que eu gosto muito é de idioma de vaca com cebolas e batatas.

(Donaldo Buchwertz (org.). Piadas para você morrer de rir. Belo Horizonte: Leitura, 2001

(...) Ao lermos um texto, colocamos em ação todo o nosso sistema de valores, crenças e atitudes que refletem o grupo social em que se deu nossa sociabilização primária, isto é, o grupo social em que fomos criados (KLEIMAN, 2010, p. 10).

O que faz a piada ser engraçada é o fato de a pessoa desconhecer o significado da palavra "idioma" e usá-la de acordo com o seu conhecimento de "língua", como um tipo de alimento, parte da vaca que pode ser comida com vários complementos.

\section{Excerto 04}


O Aluno 03 do Excerto 04 atende inicialmente ao comando do fórum de discussão, entretanto ultrapassa o limite de número de palavras - 151 -, o que torna o fórum cansativo para leitura. Não atendeu à máxima da quantidade integralmente.

\subsection{Máxima da qualidade}

A análise do Excerto 05 foi realizada com base no Fórum Temático 1 de discussão do grupo 06.

\footnotetext{
Por Aluno $04-09: 17$

Ação: Tia Maricota, durante uma conversa com a sobrinha Mariazinha, pergunta:

- Mariazinha, o que pretende fazer quando for grande como a titia?

- Um regime!
}

Ao analisar a piada, é possível constatar que o humor se dá a partir da resposta da sobrinha, ou seja, do vocábulo "regime". Isso porque, ao indagar Mariazinha, a tia é surpreendida pela imprevisibilidade da resposta dela, uma vez que esperava que a mesma relatasse a profissão, o curso que gostaria de seguir quando estivesse mais madura. Por outro lado, Mariazinha, rejeitando a forma física da tia e valendo-se do estereótipo de beleza, ou seja, do padrão de beleza imposto na atualidade pela sociedade, a magreza, sem hesitar, explicita que faria "Um regime!".

\section{Excerto 05}

Neste Excerto 05, pode-se verificar inicialmente que houve extrapolação do número de palavras. Quanto à máxima da qualidade, apresentou informações verdadeiras, entretanto não forneceu a evidência relacionada à ambiguidade da palavra "grande", o que proporcionou o efeito de humor à piada.

A seguir, no Excerto 06, a tutora do Aluno 04 faz uma mediação colaborativa, com o objetivo de elogiar a contribuição do Aluno 04 e solicitar esclarecimentos relacionados à piada apresentada. Percebe-se que, com essa tomada de atitude, o tutor provoca no aluno a necessidade de interação com todos no fórum de maneira mais eficiente.

Por Tutora 02 - Orientadora - 21:49

Aluno 04, ótima contribuição! E podemos dizer que o efeito humorístico se dá devido à ambiguidade de uma palavra específica, não é mesmo? Qual é a palavra e por que isso acontece?

Excerto 06 
Ao concluir sua fala com uma pergunta, a tutora proporciona ao aluno a possibilidade de esclarecimentos e saída da zona de conforto, trazendo evidências para a questão apresentada e afirmando o que é verdadeiro.

Dessa maneira, verifica-se que os interlocutores fazem esforços cooperativos para que o diálogo seja bem-sucedido. É importante ressaltar que o aluno não demorou muito tempo para dar a resposta (a tutora postou a mensagem no sábado à noite e o aluno já pela manhã respondeu), confirmando sua participação e interesse na discussão oportunizada pelo fórum de discussão.

\subsection{Máxima da relação}

O Excerto 07 foi retirado do "Fórum Temático 7: Avaliação das competências da matriz do ENEM - grupo 03", fórum de discussão para troca de depoimentos e considerações sobre a experiência com leitura e escrita dos alunos. A proposta: "Avalie criticamente as cinco competências da matriz do ENEM. Escreva de forma sucinta, clara e coerente, não ultrapassando 100 palavras".

Por Tutora 03 - Orientadora - 00:35

Seu texto ficou confuso, você passa de uma competência a outra sem desenvolver um raciocínio coerente. Pelo que entendi, para desenvolver a escrita a habilidade mais importante seria o uso de recursos coesivos, é isso que você quis dizer? A partir de tal conhecimento sobre os processos de coesão, o aluno seria capaz de desenvolver a solidariedade? Houve um salto no seu encadeamento; tente escrever passo a passo.

Abraços, Tutora 03

Excerto 07

A tutora, neste Excerto 08, através da mediação do fórum, percebe a violação da máxima da relação, pois o aluno não apresentou uma resposta relevante para a discussão em pauta. Busca esclarecer a fala do aluno e sugere nova reescrita no fórum.

\subsection{Máxima do modo}

Os Excertos 08 e 09 foram retirados do "Fale com a sua tutora", fórum permanente do grupo 05, o qual tem como objetivo esclarecer dúvidas com a tutora e falar sobre assuntos alheios aos temas discutidos nos fóruns temáticos das aulas. A tutora também pode usá-lo para informes importantes sobre as atividades semanais e dar instruções pertinentes ao processo de aprendizagem do aluno. 
Por Aluno $05-15: 59$

Olá, Tutora! Em relação à tarefa da aula 3, gostaria de saber se na minha resposta posso reformular a frase a fim de desfazer a ambiguidade. Por exemplo: Nenhuma flecha atingiu o alvo. Já identifiquei as possibilidades de interpretação devido à operação cognitiva de fatiamento, mas fiquei na dúvida de como desfazer a ambiguidade.

Abraços.

Excerto 08

Neste Excerto 08, o Aluno 05 apresenta a sua dúvida e exemplifica buscando esclarecer e evitar também a ambiguidade na questão. A máxima de modo não foi violada, devido à ordenação e clareza da pergunta.

Re: Fale com a sua tutora - Grupo 5

Por Tutora $04-16: 28$

Pode sim, Aluno 05.

Excerto 09

No Excerto 09, a Tutora 04, sem demora, respondeu com brevidade, clareza e concisão à pergunta do Aluno 05. Não há obscuridade e ambiguidade. Portanto, não houve violação da máxima de modo.

Os Excertos 10, 11 e 12 foram retirados do "Fórum Temático 7: Avaliação das competências da matriz do ENEM - grupo 04".

Por Tutora $05-08: 26$

Olá, pessoal! Avalie criticamente as cinco competências da matriz do ENEM.

Escreva de forma sucinta, clara e coerente, não ultrapassando 100 palavras.

Lembre-se da dinâmica AÇÃo e RÉPLICA, comentando a avaliação crítica de uma(um) colega, ou mesmo pedindo algum detalhamento que the pareça relevante.

\section{Critérios de avaliação do fórum:}

- referência às ideias do texto-base 7 (até 1 ponto).

- coerência interna, coesão e concisão (até 3 pontos).

- participação no fórum pelo menos três dias diferentes (até 1 ponto).

Mãos à obra! Abraço. Tutora 05

Excerto 10 
A Tutora 05, no comando do Excerto 10, fez uso da linguagem objetiva, concisa, coesa e coerente. Não apresentou elementos não verbais no texto, permanecendo a proposta de manutenção do limite do número de palavras a ser utilizado no fórum.

Por Aluno $06-11: 34$

Instrumentalizar o aluno para fazer uso da língua em contextos variados é uma das funções do professor. Dissertação do ENEM, por exemplo, exige registro padrão e estratégia de convencimento de que o texto encerra uma verdade (GARCIA, 1998). Para isso, o candidato deve apresentar algumas competências: habilidade com a língua escrita e domínio da norma padrão exigida pela situação; transitar por vários contextos socioculturais e produzir um texto coerente; uso dos mecanismos linguísticos como estratégia de convencimento, visando a uma intenção; organizar e interpretar informações e escrever de forma coesa; elaborar uma proposta de intervenção social, posicionando-se como cidadão.

Excerto 11

Neste Excerto 11, houve violação da máxima de modo na resposta do aluno, pois não foi breve e claro, deixando de responder de imediato à proposta do fórum.

Por Tutora $05-14: 28$

Olá Aluno 06, há alguma crítica a fazer com relação às competências apresentadas?

Abraço. Tutora 05.

Excerto 12

A tutora, no Excerto 12, ao questionar com brevidade e coesão o aluno, dá a oportunidade de nova reflexão para produção de uma resposta coerente e clara.

\section{Resultados e discussão}

Pela análise dos dados apresentados, totalizando 12 excertos de fóruns temáticos e permanentes, percebe-se que os participantes da interação, tutores e alunos, assumem o princípio cooperativo, por meio das máximas de Grice (1957), buscando a eficiência na comunicação. Clareza, coerência e concisão na troca de mensagens fortalecem a compreensão da informação que se quer passar. O diálogo é bem-sucedido ou não a partir das implicaturas conversacionais entre os participantes dos fóruns.

A análise do corpus confirma a ideia de que o aluno é o centro da aprendizagem na EaD, conforme Viana (2013). Dessa forma, fica evidente a responsabilidade do tutor, sendo professor online, quanto a suas funções pedagógica, de gerenciamento, de suporte social e técnico, relacionadas por Teles (2009), referindo-se aos "atos pedagógicos" a 
serem realizados pelo tutor. Ao gerenciar os fóruns de interação, conforme os Excertos 01 e 06, respectivamente, o tutor deu instrução direta e realizou também perguntas diretas, sem violar as máximas conversacionais (Grice, 1982).

Os Alunos 01 e 02, nos Excertos 02 e 03, ao responderem com coerência interna, coesão e concisão, conforme os critérios de avaliação do fórum específico, atendem à máxima da quantidade, interpretada por meio de uma implicatura conversacional resultado da adesão ao princípio de cooperação que guia a interação linguística entre os indivíduos (WILSON, apud GRICE, 2008).

A partir dos papéis sociais que cada um exerce no sistema de tutoria e devido à exigência explícita no início do curso do limite de cem palavras para cada postagem, o uso da objetividade, presente nos Excertos 09 e 12, é notório. Segundo Stahl et al. (2006),

ainda que o ensino online possibilite a participação de alunos do mundo todo e também que os professores trabalhem de qualquer lugar desde que conectados à internet, o ensino online implica um aumento significativo do esforço do professor por aluno.

A atuação dialógica e colaborativa do tutor, na busca de soluções, estímulo e mediação eficazes, proporciona ao aluno um ensino-aprendizagem significativo e qualitativo.

Ao observar o Excerto 07, a Tutora 3 sugere mudança e ajuste de rumo. Afirma que o aluno não atendeu à proposta de discussão no fórum e apresenta questionamentos possibilitando ao aluno uma nova reescrita para atendimento, com eficácia, da proposta. Essa atuação do tutor motiva e guia o aluno, dando a este a sensação de presença e interação contínua. Sua postagem instiga o aluno a avançar na análise crítica.

Para Stahl et al. (2006), os processos cognitivos dos participantes são influenciados pela interação social. Para tanto,

é preciso entender como os eventos da aprendizagem propriamente ditos acontecem nas interações entre os participantes. A construção de conhecimento em grupos pequenos torna-se 'internalizada pelos seus membros como aprendizagem individual e externalizada nas suas comunidades como conhecimento certificável'.

Esta construção é identificada durante o processo de ensino-aprendizagem dos alunos. No curso em estudo, foram criados nove grupos; para cada um havia um tutor 
responsável por acompanhar, apoiar, ajudar, orientar, interagir e favorecer um processo de aprendizagem realmente mediado, significativo e colaborativo.

Destaca-se, com base nas análises realizadas, que há, por parte do sujeito da aprendizagem, o tutor do curso, um incentivo à reflexão e à participação crítica, formal e autônoma nos fóruns de discussão. Essa contribuição por meio da atuação dialógica e colaborativa do tutor promove a mediação pedagógica também colaborativa.

O aluno é responsável pela organização de seu estudo. No Excerto 08, observa-se que, ao tirar dúvidas com a tutora, busca a aprendizagem autônoma, um dos objetivos da Educação a Distância. Sua expectativa é o feedback do tutor, que atua como suporte na estruturação das tarefas cognitivas, segundo a função pedagógica de Teles (2009). Como consequência, tem-se um aluno capaz de avaliar as informações e integrar-se ao processo de ensino-aprendizagem.

No Excerto 10, a Tutora 05 abre o fórum de discussão intitulado "Fórum Temático 7: Avaliação das competências da matriz do ENEM - grupo 04". Dirige-se aos alunos específicos do grupo 04 , os quais deverão interagir uns com os outros, sob sua mediação. A tutora atrai seus alunos para si, aproximando a relação entre eles, ao iniciar o fórum com um "Olá, pessoal!" e finalizando com um "Mãos à obra! Abraço. Tutora 05". Dessa maneira, o emissor (a tutora) tenta se aproximar do receptor (aluno) utilizando estratégias não tão informais, buscando a participação dele dentro da interação.

É importante observar, ainda nesse Excerto 10, a existência da categoria de feedback geral, destacada por Teles (2009), que visa, neste caso, dar a linha norteadora para a participação no fórum de discussão a partir também dos objetivos específicos propostos, bem como dos critérios de avaliação do fórum.

\section{Considerações finais}

Ao analisar os excertos apresentados, percebe-se que, por meio da mediação colaborativa, o tutor é capaz de fomentar o conhecimento de forma significativa e propiciar o desenvolvimento de habilidades e competências diversas, principalmente quando os princípios de cooperação e as máximas conversacionais são aplicados. É um processo ativo. 
Os dados apontados são fundamentais para construir uma política institucional de sistema de tutoria adequado à concepção de gestão da EaD. Deve-se buscar um modelo tutorial para atender às especificidades locais e da instituição, visando à construção de um ambiente virtual de aprendizagem eficiente, interativo e convincente.

Outros aspectos necessitam ser mais aprofundados e estudados a partir também da análise das interações nos fóruns, como a estrutura da conversação face a face, na qual há quatro componentes que estão sempre presentes: tomada de turno, sobreposição, reparo e reformulação. Com base na Teoria da Polidez, desenvolvida por Brown e Levinson (1987) no campo da Linguística, a partir das interações face a face é possível aprofundar as discussões instrucionais a distância.

\section{Referências bibliográficas}

Bakhtin, M. (2003). Os gêneros do discurso. In: Estética da criação verbal. São Paulo: Martins Fontes. p. 261-306.

Bevilaqua, D. V., \& Barreto, C. (2013). Aula 5: Conversação e discussões instrucionais. Disciplina Sistemas de Tutoria em Cursos a Distancia 5. PIGEAD/UFF.

Brown P., \& Levinson S. C. (1987). Politeness: some universals in language usage. Cambridge: Cambridge University Press.

Dotta, S., \& Giordan, M. (2007). Tutoria em Educação a Distância: um processo dialógico. Virtual Educa 2007 - Encontro Internacional Virtual Educa Brasil. São José dos Campos, SP. Disponível em: http://www.lapeq.fe.usp.br/ silviadotta/textos/dotta giordan VE 2007.pdf.

Fundação Cecierj (2014). Extensão - cursos de Formação Continuada em Letras Especialização em Ensino de Leitura e Produção Textual. Disponível em: http://especializacao. cecierj.edu.br/ava23/course/view.php?id=88. Acesso em 19 out. 2014.

Grice, H. P. (1957). The philosophical review. Reprinted in SWW. . (1982) Lógica e conversação. Fundamentos metodológicos da Linguística, v. 4, p. $81-103$. 
Ilha, F. R. S. et al. (2009). Educação a distância: a aprendizagem de professores, tutores e alunos no desenvolvimento do trabalho educativo. IX Congresso Nacional de Educação - EDUCERE (III Encontro Sul Brasileiro de Psicopedagogia) (p. 4.4354.446). Curitiba, PR. Disponível em: http://www.pucpr.br/eventos/educere/educere2009/anais/pdf/2514 1703.pdf.

Maia, C. O., \& Lannes, D. R. C. (2013). A influência da tutoria na prática da Educação a Distância. EAD em FOCO, v. 3, n. 1.

Martins, M. E., \& Garbin, T. R. (2011). Mediação em fórum na EAD, uma postura que efetiva a educação colaborativa. 170 Congresso Internacional de Educação a Distância (p. 1-10). Ouro Preto, MG. Disponível em: http://www.abed.org.br/congresso2011/cd/52.pdf.

Nobre, C. V., \& Melo, K. S de. (2011). Convergência das competências essenciais do mediador pedagógico da EaD. ESUD. VIII Congresso Brasileiro de Ensino Superior a Distância (p. 1-15). Ouro Preto, MG. Disponível em: http://www.wr3ead.com.br/ENPED\%202012/texto base etapa 2\%20(2).pdf.

Schlosser, R. L. (2010). A atuação dos tutores nos cursos de educação a distância. Revista Digital da CVA - Ricesu, vol. 6, n. 22.

Sihler, A. P., \& Ferreira, S. M. B. (2011). A afetividade mediada por meio da interação na modalidade a distância como fator preponderante para a diminuição da evasão. 170 Congresso Internacional de Educação a distância - ABED. Manaus, AM. Disponível em: http://www.abed.org.br/congresso2011/cd/116.pdf.

Stahl, G., Koschmann, T., \& Suthers, D. (2006). Aprendizagem colaborativa com suporte computacional: Uma perspectiva histórica. Disponível em: http://gerrystahl.net/cscl/CSCL Portuguese.pdf.

Teles, L. (2009). A aprendizagem por e-learning. In: LITTO, F. et al. Educação a distância: o estado da arte. São Paulo: Pearson Education do Brasil.

Viana, C. G. (2013). Estratégias de motivação em EaD: uma análise das interações tutor/alunos em um curso a distância. Dissertação (Mestrado em Letras). Universidade Federal Fluminense - UFF. Niterói, RJ. 
Vigotski, L. S. (1989). A formação social da mente: o desenvolvimento dos processos psicológicos superiores. São Paulo: Martins Fontes.

Wilson, V. (2008). Motivações pragmáticas. Manual de Linguística. São Paulo: Contexto, p. 87-110. 